\title{
Marketed under Abbreviated New Animal Drug Application
}

National Cancer Institute

\section{Source}

National Cancer Institute. Marketed under Abbreviated New Animal Drug Application. NCI Thesaurus. Code C73583.

A category specifying that a product is marketed under an Abbreviated New Animal Drug Application. 